\title{
Prevention and Reversal of Morphine-Induced Tolerance by Novel Muscarinic Receptor Agonist in Rats with Neuropathic Pain
}

Carlos ES Monteiro ${ }^{1}$, Nailton M Nascimento-Júnior ${ }^{2}$, Margarete M Trachez ${ }^{3}$, Roberta Tesch ${ }^{1}$, Thaiana CF Mendes ${ }^{1}$, Carlos AM Fraga ${ }^{1}$, Carlos MR de Sant'Anna $^{4}$, Gisele Zapata-Sudo ${ }^{1}$, Eliezer J Barreiro ${ }^{1}$ and Roberto T Sudo ${ }^{1 *}$

${ }^{1}$ Instituto de Ciências Biomédicas, Universidade Federal do Rio de Janeiro, Rio de Janeiro, Brasil

2Instituto de Química, Estadual Paulista "Júlio de Mesquita Filho", Araraquara-SP, Brasil

${ }^{3}$ Departamento de Anestesiologia, Universidade Federal Fluminense, RJ, Brasil

${ }^{4}$ Instituto de Ciências Exatas, Universidade Federal Rural do Rio de Janeiro, RJ, Brasil

*Corresponding author: Roberto Takashi Sudo, Full Professor, Universidade Federal do Rio de Janeiro, Centro de Ciências da Saúde, Bloco J, Sala 14, Rio de Janeiro, 21941-902, Brazil, Tel: 55-21-39386505; E-mail: rtsudo@icb.ufrj.br

Received date: February 20, 2015; Accepted date: April 08, 2015; Published date: April 13, 2015

Copyright: (2015 Monteiro CES. This is an open-access article distributed under the terms of the Creative Commons Attribution License, which permits unrestricted use, distribution, and reproduction in any medium, provided the original author and source are credited.

\begin{abstract}
Objective: To investigated the effectiveness of a novel M2 muscarinic receptor agonist, the pyrazolo[3,4b]pyrrolo[3,4-d]pyridine derivative LASSBio-981, on the prevention and reversal of morphine-induced antinociceptive tolerance in a rat model of neuropathic pain.

Methods: Thermal hyperalgesia and mechanical allodynia were induced in rats by spinal nerve ligation in L5. After rats displayed signs of sustained pain, continuous infusions of morphine were delivered in the peritoneum through osmotic mini-pumps. LASSBio-981 was daily administered by oral gavage starting at the same day of morphine infusion (prevention protocol) or after development of morphine-induced tolerance (reversion protocol). To access the mechanism of LASSBio-981 action on the M2 muscarinic receptor, a single dose of the specific antagonist, methoctramine, was injected through intrathecal route. In addition, the crystallographic structure of human M2 muscarinic receptor and the computer program GOLD 5.2 (genetic algorithm software: CCDC) simulated the docking of LASSBio-981 into the orthosteric binding site of the receptor.
\end{abstract}

Results: Morphine inhibited the thermal and mechanical hyperalgesia induced by spinal nerve ligation and this effect decreased time-dependently and totally disappeared (tolerance) 16 days of infusion. LASSBio-981 prevented and reversed morphine-induced antinociceptive tolerance. Treatment with methoctramine inhibited LASSBio-981 effect in reversing the morphine-induced tolerance suggesting the involvement of M2 muscarinic receptor activation. This hypothesis was strengthened because the molecular docking analyses determined that LASSBio-981 interacts with the orthosteric binding site of the M2 muscarinic receptor.

Conclusion: This study provides evidence that a novel M2 muscarinic receptor agonist (LASSBio-981) may prevent and reverse morphine-induced tolerance in rat model of neuropathic pain.

Keywords: Morphine tolerance; Hyperalgesia; Allodynia; LASSBio-981; Opioide receptors; M2 muscarinic receptor; Methoctramine; Chronic pain; Osmotic mini-pump

\section{Introduction}

Recent studies estimated that $7-8 \%$ of the general population suffers from chronic pain with neuropathic features [1]. Unfortunately, current pharmacotherapies used to treat the main symptoms of this disorder, hyperalgesia and allodynia, are not completely effective [2]. Current treatments utilize several classes of chemically distinct drugs, including opioids, tricyclic antidepressants (TCAs), alpha-2 adrenergic receptor agonists and anticonvulsants [3-5]. Of these treatments, opioids are the most effective at managing chronic pain. There are three known opioid receptor subtypes, $\mu, \delta$, and $\kappa$. Among them, the $\mu$-receptor has been the target of drug development for pain medication [6]. Morphine is a $\mu$-receptor agonist that is very effective in the treatment of chronic pain; however its prolonged use may be followed by severe side effects and physical dependence. Several studies have shown that chronic morphine treatment results in tolerance and hyperalgesia [7-9].

The development of opioid tolerance is typically measured as a change in antinociceptive or analgesic responses and likely involves several mechanisms. There is evidence that the analgesic effects of $\mu$ opioid agonist are reduced in a nerve ligation injury animal model of chronic pain [10]. Chronic morphine exposure triggers an intracellular signaling cascade that results in opioid receptors desensitization and endocytosis. Following endocytosis, receptors can be recycled and moved to cell membrane, stored in an intracellular compartment, or degraded in the cell cytoplasm $[11,12]$. Morphine-induced tolerance is also associated with activation of glia in the spinal cord, which could produce several neuroexcitatory molecules as nitric oxide, prostaglandins, adenosine triphosphate, excitatory amino acids and reactive oxygen species (ROS) [13]. The neuroexcitatory molecules and ROS enhance pain and may directly contribute to the mechanism of morphine-induced tolerance [14]. 
Citation: Monteiro CES, Nascimento-Júnior NM, Trachez MM, Tesch R, Mendes TCF, et al. (2015) Prevention and Reversal of MorphineInduced Tolerance by Novel Muscarinic Receptor Agonist in Rats with Neuropathic Pain. J Neurol Neurophysiol 6: 282. doi: $10.4172 / 2155-9562.1000282$

Page 2 of 7

Clinical and pre-clinical studies suggest that cholinergic mechanisms in the spinal cord and primary afferents fibers are also involved to analgesic effects. Acetylcholinesterase inhibitors and muscarinic acetylcholine receptor agonists produce analgesia in humans and animals in part, by activating M2 muscarinic receptors that inhibit nociceptive input to primary sensory neurons [15]. M2 muscarinic receptors are up-regulated in animals with diabetic neuropathy and peripheral nerve injury $[15,16]$. Acetylcholine modulates pain by increasing endogenous opiate peptides in the rat spinal cord [17]. Morphine dependence and withdrawal can produce changes in cholinergic signaling [18].

Based on the chemical structure of zolpidem, [a gammaaminobutyric acid (GABA)A receptor agonist], novel pyrazolo[3,4-b] pyrrolo[3,4-d]pyridine derivatives have been synthesized for use in pain modulation. Among these new derivatives, the antinociceptive effect of LASSBio-872, LASSBio-873, LASSBio-980 and LASSBio-981 has been characterized in hot plate, formalin, carrageenan and neuropathic pain models [19-21].

In model of neuropathic pain, the analgesic effect of LASSBio-873 were inhibited by intrathecal injection of methoctramine, suggesting that M2 muscarinic receptors are involved in LASSBio-873-induced analgesia [20]. The muscarinic receptor-mediated analgesia has been demonstrated to occur in the spinal cord [22].

Of the pyrazolo[3,4-b]pyrrolo[3,4-d]pyridine derivatives, we recently demonstrated that the oral route administration of LASSBio-981 compound produced greater analgesia than the LASSBio-873 in a rat model of chronic pain (unpublished observations). Thus, in the present study, we evaluated the antinociceptive effects of LASSBio-981, using morphine-induced tolerance in a rat model of neuropathic pain. In addition, we also used molecular docking analysis to characterize the interactions of LASSBio-981 with the M2 muscarinic acetylcholine receptor.

\section{Methods}

\section{Animals and housing}

All protocols used were blinded and approved by the Animal Care and Use Committee at Universidade Federal do Rio de Janeiro, following the guidance of the Brazilian National Council of Experimental Animal Use Control (2014). Adult male Wistar rats (180-220 g) were housed on a $12 \mathrm{~h}$ light/dark cycle (light on at 6:00 a.m.) with ad libitum access to food and water. Room temperature and relative humidity were maintained at $22 \pm 1^{\circ} \mathrm{C}$ and $60 \pm 5 \%$, respectively. Animals were acclimated to the laboratory for at least 30 min prior to the experimental testing and were randomly divided into different groups $(\mathrm{n}=4$ per group calculated using statistical power analysis) [23].

\section{Drugs}

Morphine sulfate and amitriptyline hydrochloride were donated by Cristália Produtos Químicos e Farmacêuticos Ltda (Itapira, SP, Brazil). Pyrazolo [3,4-b] pyrrolo [3,4-d] pyridine (LASSBio-981) was synthesised and provided by the Laboratório de Avaliação e Síntese de Substâncias Bioativas (LASSBio) at UFRJ. Methoctramine tetrahydrochloride hydrate was purchased from Sigma-Aldrich (St Louis, MO, USA). All chemicals were dissolved in $0.9 \%$ saline, except for LASSBio-981, which was dissolved in dimethyl sulfoxide (DMSO; Gaylord Chemical Company L.L.C, USA).

\section{Surgical procedures}

Neuropathic pain was induced by spinal nerve ligation (SNL), according to previously published methods [21]. Briefly, rats were anesthetized with ketamine (100 $\mathrm{mg} / \mathrm{kg}$, intraperitoneal [i.p.]) and xylazine $(5 \mathrm{mg} / \mathrm{kg}$, i.p.). Skin around the surgical site was sterilized with $0.5 \%$ chlorhexidine. An incision $(\sim 2.5 \mathrm{~cm})$ was made over the L5S1 spinal segment and the paravertebral musculature was retracted from the vertebral transverse processes. The L6 transverse process was partially removed, exposing the L4 and L5 spinal nerves. The L5 spinal nerve was ligated with 6-0 silk suture. Animals were individually housed after surgery during all time of study.

\section{Nociceptive behavioral testing: thermal hyperalgesia and mechanical allodynia}

Paw withdrawal latency was measured after application of radiant heat to the hind paw of animals [24,25]. Hind paw withdrawal was detected as an interruption in the light beam heat source. Latency was defined as the duration of time until an interruption occurred as determined by a Dynamic Plantar Esthesiometer (model 37450, Ugo Basile SRL, ITALY). To prevent tissue damage, maximal latency was set at $30 \mathrm{~s}$. Latency values were calculated as the average response of three measurements. Thermal hyperalgesia was defined as significantly shorter withdrawal latencies in SNL animals compared to control.

To measure mechanical allodynia, a Digital Analgesimeter pressure transducer (model EFF301, Insight, SP, Brazil) was used to apply increasing pressure of a trough plastic tip ( $1 \mathrm{~mm}$ external diameter) to the paw [26-28]. The mechanical threshold was defined as the pressure applied when the animal lifted its paw. The average value of five trials was taken as the mechanical threshold. To avoid tissue damage, maximal pressure was set to $120 \mathrm{~g}$. Mechanical allodynia was defined as a statistically significant reduction in the mechanical threshold of SNL-treated animals compared to controls.

\section{Morphine-induced tolerance}

After thermal hyperalgesia and mechanical allodynia had developed and stabilized 7 days SNL surgery osmotic minipumps (Alzet, Cupertino, CA) were implanted for infusion of morphine (2.5 $\mathrm{mg} / \mathrm{kg} / \mathrm{d}$ ) for 16,23 or 30 days at a constant delivery rate of $2.5 \mu \mathrm{l} / \mathrm{h}$. The pump size was selected to allow at least 30 days of continuous morphine infusion. In SNL animals, tolerance to morphine-induced analgesia emerged after as few as 3 days of continuous morphine treatment. The tolerance effect was completely developed by 16 days, when the pain reactions of SNL-treated animals returned to control level. LASSBio-981 (10 mg/kg/d), amitriptyline $(10 \mathrm{mg} / \mathrm{kg} / \mathrm{d}$, positive control), or vehicle (DMSO, $100 \mu \mathrm{l} / \mathrm{d}$ ) was administered orally for the remaining 14 days (therapeutic or reversion protocol). For the prophylactic or prevention protocol, LASSBio-981 (10 $\mathrm{mg} / \mathrm{kg} / \mathrm{d})$, amitriptyline $(10 \mathrm{mg} / \mathrm{kg} / \mathrm{d})$ or vehicle (DMSO, $100 \mu \mathrm{l} / \mathrm{d}$ ) was administered from 7 to 16 days after surgery.

\section{Mechanism of action of LASSBio-981}

To investigate the potential involvement of M2 muscarinic receptors as targets for LASSBio-981, methoctramine $(10 \mu \mathrm{g}$ in $40 \mu \mathrm{l})$ was delivered by intrathecal administration into the L4-L5 intervertebral space under light anesthesia (sevoflurane 3 vol\% gas/ gas) [24]. Methoctramine treatment occurred after 7 days of oral treatment with LASSBio-981 $(10 \mathrm{mg} / \mathrm{kg} / \mathrm{d})$. Nociceptive test started 15 
Citation: Monteiro CES, Nascimento-Júnior NM, Trachez MM, Tesch R, Mendes TCF, et al. (2015) Prevention and Reversal of MorphineInduced Tolerance by Novel Muscarinic Receptor Agonist in Rats with Neuropathic Pain. J Neurol Neurophysiol 6: 282. doi: $10.4172 / 2155-9562.1000282$

Page 3 of 7

min after animals recovered from anesthesia. Paw withdrawal latency was measured before and 15, 30, 60, 90, 120, and $150 \mathrm{~min}$ after methoctramine administration.

\section{Docking of LASSBio-981 to the human M2 muscarinic receptor}

Molecular docking studies were performed with the crystallographic structure of human M2 muscarinic receptor (Protein Data Bank, PDB ID: 3UNO) [25]. GOLD 5.2 (genetic algorithm software: CCDC) was used to simulate docking of LASSBio-981 into the orthosteric binding site of the receptor. A distance of $10 \AA$ from the Tyr104 residue was used to define the set of amino acid residues selected as the binding site. To validate the methodology, the GoldScore fitness function was used to perform a re-docking study using the structure of the M2 muscarinic receptor antagonist 3quinuclidinyl-benzilate (QBN).

The structure of LASSBio-981 was energy-minimized by the ab initio HF/3-21G method and Spartan'08 software (Wavefunction Inc.). Docking runs with the optimized LASSBio-981 structure were conducted in triplicate; each run generated 10 poses. The pose with the highest score of all runs was chosen for analysis. The scale of the score gives an indication of pose fit, with higher scores indicating a docking result.

\section{Statistical analysis}

Data were expressed as the mean \pm standard error of the mean (S.E.M.). One-way analysis of variance (ANOVA) with NewmanKeuls post-test was used for multiple group comparison. $\mathrm{P}<0.05$ was considered statistically significant.

\section{Results}

\section{Morphine-induced antinociceptive tolerance}

In SNL-treated animals thermal stimulation-induced paw withdrawal latency decreased over 7 days after SNL $(11.4 \pm 0.2$ to $7.5 \pm$ $0.3 \mathrm{~s} ; \mathrm{P}<0.05)$, but increased after 1 day of continuous morphine infusion $(2.5 \mathrm{mg} / \mathrm{kg} / \mathrm{d}$, i.p.; $12.0 \pm 1.4 \mathrm{~s} ; \mathrm{P}<0.05$; Figure $1 \mathrm{~A})$. Treatment with vehicle did not cause any antinociceptive effect. Morphine tolerance developed over the first 16 days of continuous morphine exposure, with withdrawal latency returning to pre-morphine levels by day $16(8.3 \pm 1.5 \mathrm{~s}$; Figure 1A). The mechanical stimulation threshold in SNL-treated animals decreased 7 days after SNL treatment $(35.9 \pm$ 0.3 to $16.2 \pm 0.4 \mathrm{~g} ; \mathrm{P}<0.05)$, but increased after 1 days of continuous morphine infusion $(34.6 \pm 0.6 \mathrm{~g} ; \mathrm{P}<0.05)$. The mechanical stimulation withdrawal threshold decreased over the first 16 days of continuous morphine infusion, returning to pre-morphine levels by day 16 (18.2 \pm 1.0 g; Figure 1B).

\section{Effect of LASSBio-981 on morphine-induced tolerance}

Morphine was infused for 23 days after the animals were submitted to SNL and after thermal hyperalgesia and mechanical allodynia were established. The thermal stimulation-induced paw withdrawal latency was decreased in all groups 7 days after SNL treatment (LASSBio-981, amitriptyline and DMSO; $\mathrm{P}<0.05, \mathrm{n}=4$ per group; Figure $2 \mathrm{~A}$ ), but increased back to control levels after 1 day of continuous morphine infusion. Morphine-induce tolerance developed in a time-dependent manner. Co-administration of oral amitriptyline $(10 \mathrm{mg} / \mathrm{kg} / \mathrm{d})$ did not change the course of morphine-induced tolerance; however, oral LASSBio-981 (10 mg/kg/d) completely blocked this effect (Figure 2A).

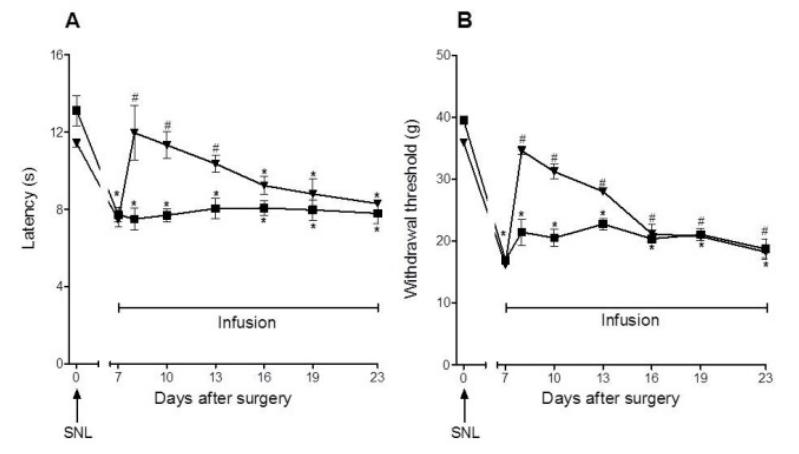

Figure 1: Time-course of morphine-induced tolerance. Morphine was infused $(2.5 \mathrm{mg} / \mathrm{kg} / \mathrm{d}$, i.p.) through an osmotic mini-pump during 16 days in rats submitted to SNL. A) Latency in response to thermal stimulation in rats submitted to SNL. B) Withdrawal threshold in response to mechanical stimulation applied to the paw of rats submitted to SNL. ( $\bullet$ ) saline infusion or (v) morphine infusion. Data represent the mean \pm SEM $(n=4) .{ }^{*} \mathrm{P}<0.05$ versus day 0 . ${ }^{\#} \mathrm{P}<0.05$ versus day 7 .

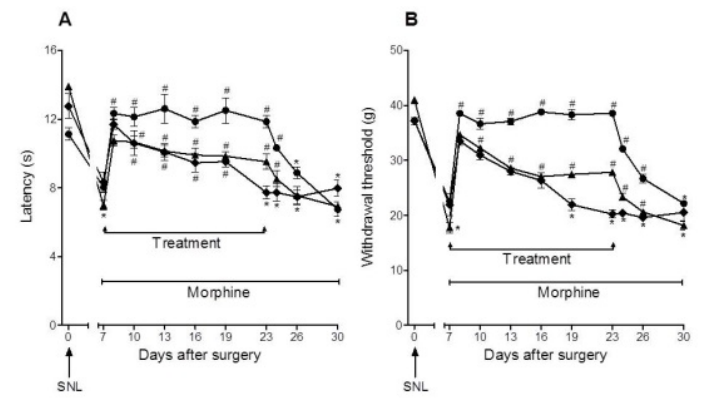

Figure 2: Prevention of the morphine-induced tolerance by LASSBio-981 or amitriptyline. Morphine was infused $(2.5 \mathrm{mg} / \mathrm{kg} / \mathrm{d}$, i.p.) through an osmotic mini-pump during 23 days. A) Latency in response to thermal stimulation in rats submitted to SNL. B) Withdrawal threshold in response to mechanical stimulation applied to the paw of rats submitted to SNL. $(\bullet)$ LASSBio-981 (10 $\mathrm{mg} / \mathrm{kg}),(\boldsymbol{\Lambda})$ amitriptyline $(10 \mathrm{mg} / \mathrm{kg})$ or ( $)$ vehicle (DMSO) was administered daily by gavage during 16 days associated with the infusion of morphine. Data represent the mean \pm SEM $(\mathrm{n}=4)$. ${ }^{\star} \mathrm{P}<0.05$ versus day $0 ;{ }^{\#} \mathrm{P}<0.05$ versus day 7 .

The mechanical stimulation withdrawal threshold was reduced into to all groups 7 days after SNL treatment (LASSBio-981, amitriptyline and DMSO; $\mathrm{P}<0.05 ; \mathrm{n}=4$; Figure $2 \mathrm{~B}$ ), but returned to control levels after 1 day of continuous morphine infusions. Again, tolerance to 
Citation: Monteiro CES, Nascimento-Júnior NM, Trachez MM, Tesch R, Mendes TCF, et al. (2015) Prevention and Reversal of MorphineInduced Tolerance by Novel Muscarinic Receptor Agonist in Rats with Neuropathic Pain. J Neurol Neurophysiol 6: 282. doi: $10.4172 / 2155-9562.1000282$

Page 4 of 7

morphine developed in a time-dependent manner. Co-administration of oral amitriptyline $(10 \mathrm{mg} / \mathrm{kg} / \mathrm{d})$ prevented tolerance after 12 to 16 days of administration (Figure 2B). However, morphine-induced tolerance was completely prevented by 16 days of LASSBio-981 (10 $\mathrm{mg} / \mathrm{kg} / \mathrm{d}$ ) administration (Figure $2 \mathrm{~B}$ ). This effect was spontaneously reversed by discontinuation of LASSBio-981 treatment.

\section{Effect of LASSBio-981on reversal of morphine-induced tolerance}

The thermal and mechanical stimulation-induced paw withdrawal responses were reduced 7 days after SNL treatment $(\mathrm{P}<0.05)$. However, these response increased back to control levels after 1 day of continuous morphine infusion (Figures $3 \mathrm{~A}$ and $3 \mathrm{~B}$ ). Morphine gradually developed tolerance over 16 days at which time pain responses returned to pre-morphine levels. After 14 days of oral administration, both amitriptyline $(10 \mathrm{mg} / \mathrm{kg} / \mathrm{d} ; 8.0 \pm 0.3 \mathrm{~s}$ to $10.2 \pm$ $0.5 \mathrm{~s} ; \mathrm{P}<0.05)$ and LASSBio- $981(10 \mathrm{mg} / \mathrm{kg} / \mathrm{d} ; 7.7 \pm 0.2$ to $13.3 \pm 1.2 \mathrm{~s}$; $\mathrm{P}<0.05)$ increased the thermal stimulation-induced withdrawal latency. LASSBio-981 was more effective than amitriptyline reversing the morphine-induced tolerance (Figure 3A).

Amitriptyline and LASSBio-981 both increased the mechanical stimulation-induced withdrawal threshold $(19.9 \pm 1.0$ to $29.0 \pm 1.1 \mathrm{~g}$ and $21.0 \pm 0.6$ to $37.0 \pm 0.1 \mathrm{~g}$, respectively; $\mathrm{P}<0.05)$. LASSBio-981 was more effective than amitriptyline in reversing tolerance to antinociceptive effect of morphine. No effects of vehicle
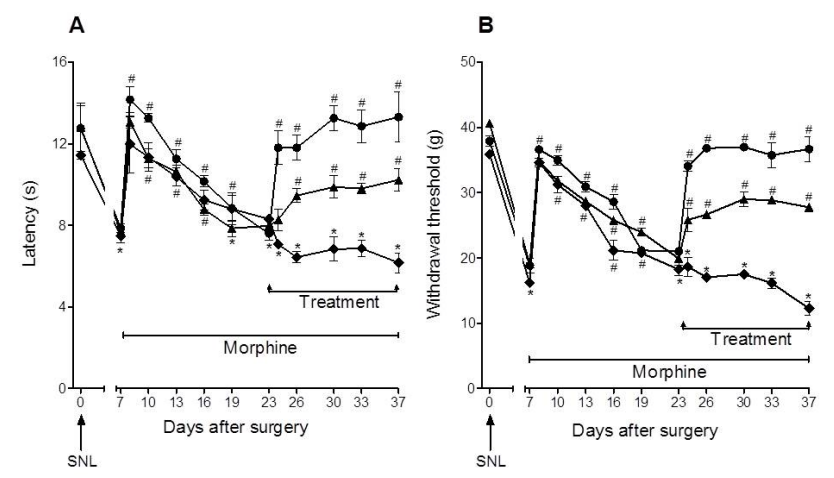

Figure 3: Reversal of the morphine-induced tolerance by LASSBio-981 or amitriptyline. Morphine was infused $(2.5 \mathrm{mg} / \mathrm{kg} / \mathrm{d}$, i.p.) through an osmotic mini-pump during 30 days. LASSBio-981 $(10 \mathrm{mg} / \mathrm{kg})$, amitriptyline $(10 \mathrm{mg} / \mathrm{kg})$ or vehicle was administered daily by gavage during 14 days after development of morphine tolerance. $(\bullet)$ LASSBio-981, ( $\mathbf{\Lambda}$ )amitriptyline, $(\bullet)$ vehicle. A) Latency in response to thermal stimulation in rats submitted to SNL. B) Withdrawal threshold in response to mechanical stimulation applied to the paw of rats submitted to SNL. Data represent the mean $\pm \operatorname{SEM}(\mathrm{n}=4) .{ }^{*} \mathrm{P}<0.05$ versus day $0 ;{ }^{\#} \mathrm{P}<0.05$ versus day 7 .

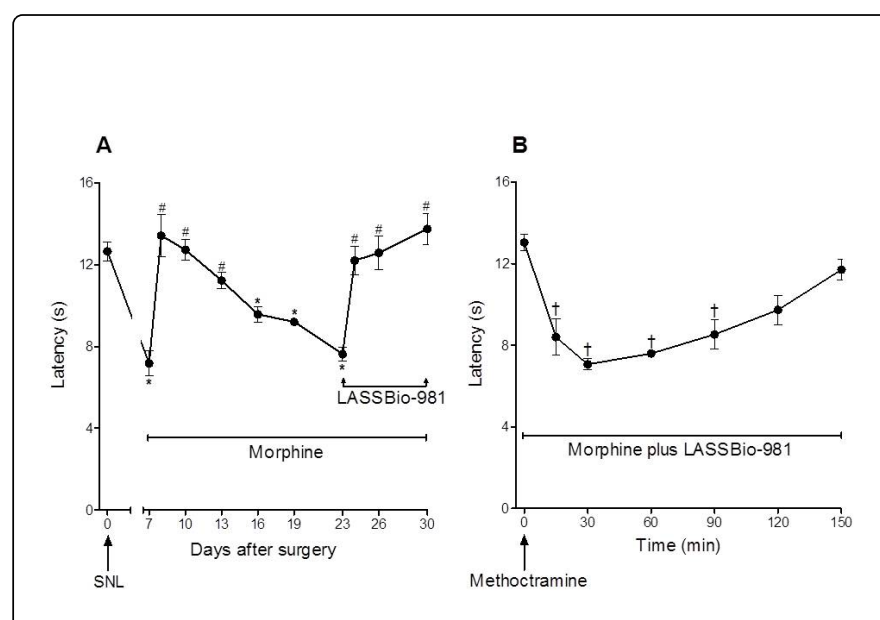

Figure 4: Morphine-induced tolerance in the presence of methoctramine, an $\mathrm{M} 2$ cholinergic receptor antagonist and LASSBio-981. A) Latency in response to thermal stimulation in rats submitted to SNL. LASSBio-981 (10 mg/kg) was administered daily by gavage during 7 days after establishment of morphine tolerance (16 days infusion). B) After treatment with LASSBio-981, methoctramine $(10 \mu \mathrm{g})$ was administered by intrathecal route. Data are represented as mean $\pm \operatorname{SEM}(\mathrm{n}=4) .{ }^{*} \mathrm{P}<0.05$ versus day $0 ;{ }^{\#} \mathrm{P}<0.05$ versus day $7 ;{ }^{\dagger} \mathrm{P}<0.05$ versus time 0 .

administration (DMSO) were found on reversal of morphine tolerance (Figure 3B).

\section{Analgesic mechanism of LASSBio-981 on morphine tolerance}

Daily oral administration of LASSBio-981 (10 mg/kg/d) completely reversed morphine-induced tolerance (Figure 4A). Intrathecal methoctramine $(10 \mu \mathrm{g})$ completely inhibited this effect within $30 \mathrm{~min}$ of administration followed by spontaneous recovery of the LASSBio-981-induced reversal of morphine tolerance (Figure 4B).

\section{Molecular docking analysis}

The RMSD of redocked QBN and co-crystallized QBN structures was $0.43 \AA$ for all atoms validating the chosen fitness function. Due to the proximity of the Thr187 side chain and a hydrogen bond acceptor group in LASSBio-981, we performed a semi-rigid docking conferring flexibility to the Thr187 side chain. The semi-rigid methodology provides a higher score than the rigid methodology and the best associated pose was chosen for further analyses.

Molecular docking analysis revealed that LASSBio-981 interacted primarily in the orthosteric binding site of the human M2 muscarinic receptor. This interaction was with two hydrogen bonds between the pyrazolo-pyridine moiety of LASSBio-981 and the hydroxyl groups of residues Tyr426 and Thr187 of the M2 muscarinic receptor. In addition, LASSBio-981 exhibited hydrophobic interactions with a pocket of amino acids formed by the side chains of residues Tyr104, Trp155, Trp400 and Tyr403 (Figure 5). 
Citation: Monteiro CES, Nascimento-Júnior NM, Trachez MM, Tesch R, Mendes TCF, et al. (2015) Prevention and Reversal of MorphineInduced Tolerance by Novel Muscarinic Receptor Agonist in Rats with Neuropathic Pain. J Neurol Neurophysiol 6: 282. doi: $10.4172 / 2155-9562.1000282$

Page 5 of 7

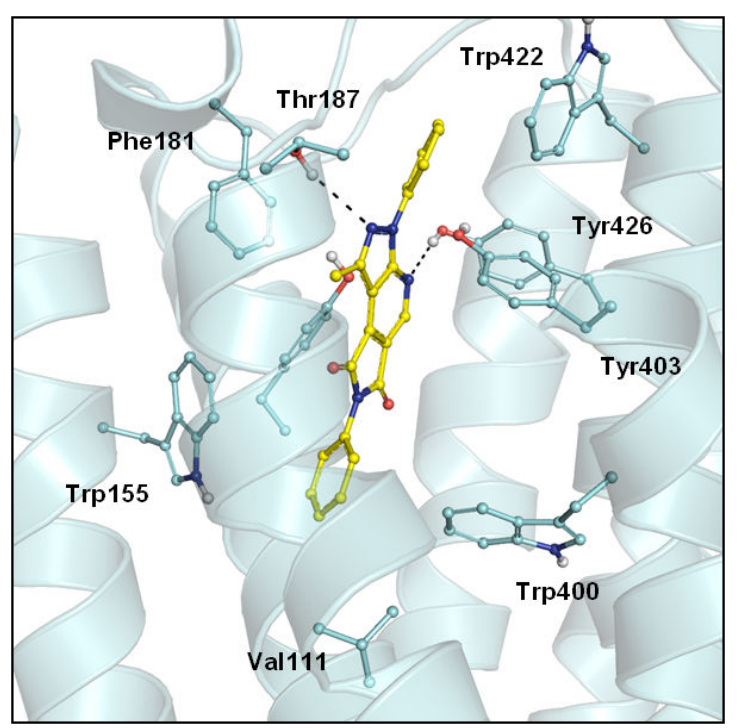

Figure 5: Predicted binding mode of the compound LASSBio-981 in the M2 muscarinic receptor. Dashed lines represent hydrogen bond interactions.

\section{Discussion}

Morphine is very effective treatment for pain, but prolonged use can result in several serious side effects, including tolerance, crosstolerance to others $\mu$-opioids agonists and physical dependence. The current study found that 16 days of continuous morphine exposure (via osmotic mini-pumps) in SNL-treated rats produced a complete tolerance in reducing thermal hyperalgesia and mechanical allodynia. Osmotic mini-pumps are a reliable methods for continuous drug infusion that overcome the plasma drug concentration fluctuation associated with intermittent administration [29,30]. Here, we used this method to investigate the effect of a zolpidem derivative, LASSBio-981, on the prevention or reversal of the morphine-induced tolerance in an animal model of neuropathic pain.

Chronic morphine use has been suggested to produce tolerance through a number of different mechanisms, including desensitization and endocytosis of opioid receptors [12], activation of glia cells [31], sustained morphine-mediated augmentation of spinal calcitonin generelated peptide immunoreactivity [29], increased spinal NK1 receptor and NMDA receptor expression $[8,30]$.

Previously, we demonstrated that a new zolpidem analogue, LASSBio-873, was effective at reducing thermal hyperalgesia and mechanical allodynia in rats submitted to SNL-treatment [20]. The structural difference between LASSBio-981 (used in the current study) and LASSBio873 is the presence of a nitro group in the para position of one of the phenyl rings connecting the pyrazolo[3,4-b]pyrrolo[3,4d]pyridine moiety of LASSBio-873. Oral administration of LASSBio-981 has been found to produce greater pain reduction than LASSBio-873 in an animal model of neuropathic pain (data not shown). Thermal hyperalgesia and mechanical allodynia induced by SNL rats were partially (ca. 50\%) reversed by treatment with LASSBio-981 [31]. The antinociceptive effect of LASSBio-981 was sustained with no observation of tolerance; however animals were short-term treated for 7 days. Notably, LASSBio-981, but not amitriptyline, completely prevented and reversed morphine-induced tolerance even after 14 days of treatment. Combination treatment with morphine and LASSBio-981 was more effective than with LASSBio-873 alone [20]. The effects of LASSBio-981 were inhibitted by intrathecal administration of methoctramine, suggesting that the M2 muscarinic receptor-signaling pathway aids in mediating these effects. Those effects could occur through direct activation of muscarinic receptors or by inhibition of the enzyme acetylcholinesterase (AChE) which in turn could increase ACh level. However, LASSBio-981 did not inhibit the activity of AchE (< $10 \%$, data not shown), indicating that the action of LASSBio-981 occurs by direct interaction with muscarinic receptors.

Morphine tolerance can be reduced in rats by several other compounds, including lamotrigine (an anticonvulsant drug) [33], vigabatrin (an antiepileptic drug) [34] and gabapentin (an antiepileptic drug) [35]. Tricyclic antidepressants (TCAs), commonly used for the treatment of major depressive disorders, are also used in the treatment of neuropathic pain. In agreement with others [36], here we found that the TCA amitriptyline attenuated tolerance only to the antinociceptive effects of morphine.

Several reports have shown that the cholinergic system plays an important role in pain modulation. The intrathecal administration of acetylcholine increased L-enkephalin, $\beta$-endorphin and dynorphin A1-13 concentrations in the rat spinal cord. This effect was reduced by either the non-selective muscarinic receptor antagonist atropine or the nicotinic receptor antagonist gallamine [17]. The activation of M2 muscarinic receptors regulated glutamate release in spinal cord primary afferent neurons was demonstrated using electrophysiological technique [37]. In addition, the M3 and M2/M4 muscarinic receptor subtypes are involved in regulation of glutamate release from a subpopulation of interneurons in the rat spinal cord [37].

Following tight ligation of the L5 and L6 spinal nerves in rats, there was an increase in M2 muscarinic receptor immunoreactivity in both ipsilateral and contralateral DRG neurons [15]. In a streptozotocininduced neuropathic pain model in rats, intrathecal administration of the non-selective muscarinic receptor agonist, muscarine, had antinociceptive effects [16]. Antinociceptive effect produced by muscarinic receptor activation has also been demonstrated with direct cholinergic agonists [38] and acetylcholinesterase inhibitors [39]. Intrathecal administration of a nicotinic agonist has also been shown to produce antinociceptive effects [40].

The intrathecal administration of the muscarinic receptor antagonist atropine and the M1/M4 antagonist pirenzepine produced a dose-dependent inhibition of morphine-induced antinociception. Interestingly, neither the M2 muscarinic receptor antagonist methoctramine nor the M3 muscarinic receptor antagonist 4-DAMP was found to inhibit morphine-induced antinociception [41].

The elucidation of the crystal structure of the human M2 muscarinic receptor combined with mutagenesis data has led to important advancements in molecular recognition of agonists and antagonists binding sites. LASSBio-981 was found to interact with amino acids residues involved primarily in agonist binding sites, such as Trp155 and Trp400 [42]. Importantly, using semi-rigid methodology, we were able to establish a hydrogen bond with LASSBio-981. We determined that the binding site was near the Thr187 residue of M2 muscarinic receptor. In support of our findings that LASSBio-981 is a potencial M2 muscarinic receptor agonist, 
Citation: Monteiro CES, Nascimento-Júnior NM, Trachez MM, Tesch R, Mendes TCF, et al. (2015) Prevention and Reversal of MorphineInduced Tolerance by Novel Muscarinic Receptor Agonist in Rats with Neuropathic Pain. J Neurol Neurophysiol 6: 282. doi: $10.4172 / 2155-9562.1000282$

Page 6 of 7

others have shown that the Thr187 residue is involved in the binding of agonists but not antagonists [42].

\section{Conclusion}

Our findings suggest that LASSBio-981 can prevent and reverse the development of morphine tolerance. This study also indicates that M2 muscarinic receptor activation can enhance morphine-induced antinociception.

\section{Acknowledgments}

This work was supported by grants of Conselho Nacional de Desenvolvimento Cientifico e Tecnológico (CNPq), Coordenação de Aperfeiçoamento de Pessoal de Nível Superior (CAPES), Fundação Universitária Jose Bonifácio (FUJB), Programa de Apoio a Núcleos de Experiência (PRONEX), Fundacao Carlos Chagas Filho de Amparo a Pesquisa do Estado do Rio de Janeiro (FAPER) and Instituto Nacional de Ciência e Tecnologia/Fármacos (CNPQ, Brazil).

\section{References}

1. Torrance N, Ferguson JA, Afolabi E, Bennett MI, Serpell MG, et al. (2013) Neuropathic pain in the community: more under-treated than refractory? Pain 154: 690-699.

2. Baron R (2006) Mechanisms of disease: neuropathic pain--a clinical perspective. Nat Clin Pract Neurol 2: 95-106.

3. Cepeda MS, Farrar JT (2006) Economic evaluation of oral treatments for neuropathic pain. J Pain 7: 119-128.

4. Hayashida KI, Eisenach JC (2010) Spinal a2-adrenoceptor mediated analgesia in neuropathic pain reflects brain derived nerve growth factor and changes in spinal cholinergic neuronal function. Anesthesiology 113: 406-412.

5. Kissin I1 (2010) The development of new analgesics over the past 50 years: a lack of real breakthrough drugs. Anesth Analg 110: 780-789.

6. Pan HL, Wu ZZ, Zhou HY, Chen SR, Zhang HM, et al. (2008) Modulation of pain transmission by G-protein-coupled receptors. Pharmacol Ther 117: 141-161.

7. Romero A, Miranda HF, Puig MM (2010) Antinociceptive effects of morphine, fentanyl, tramadol and their combination, in morphinetolerant mice. Pharmacol Biochem Behav 97: 363-369.

8. Vera-Portocarrero LP, Zhang ET, King T, Ossipov MH, Vanderah TH, et al. (2007) Spinal NK-1 receptor expressing neurons mediate opioidinduced hyperalgesia and antinociceptive tolerance via activation of descending pathways. Pain 129: 35-45.

9. Liang DY, Li X, Clark JD (2013) Epigenetic regulation of opioid-induced hyperalgesia, dependence, and tolerance in mice. J Pain 14: 36-47.

10. Zanjani TM, Saghaei E, Ameli H, Sabetkasaei M (2013) Anti-allodynic effect of nefopam and morphine in a rat model of neuropathic pain. Novel Biomed 1: 16-22.

11. Martini L, Whistler JL (2007) The role of mu opioid receptor desensitization and endocytosis in morphine tolerance and dependence. Curr Opin Neurobiol 17: 556-564.

12. Quillinan N, Lau EK, Virk M, von Zastrow M, Williams JT (2011) Recovery from mu-opioid receptor desensitization after chronic treatment with morphine and methadone. J Neurosci 31: 4434-4443.

13. Song P, Zhao ZQ (2001) The involvement of glial cells in the development of morphine tolerance. Neurosci Res 39: 281-286.

14. Gong N, Li XY, Xiao Q, Wang YX (2014) Identification of a novel spinal dorsal horn astroglial d-amino acid oxidase-hydrogen peroxide pathway involved in morphine antinociceptive tolerance. Anesthesiology 2014, 120: 962-975.

15. Hayashida KI, Bynum T, Vincler M, Eisenach JC (2006) Inhibitory M2 muscarinic receptors are upregulated in both axotomized and intact small diameter dorsal root ganglion cells after peripheral nerve injury. Neuroscience 140: 259-268.

16. Chen SR, Pan HL (2003) Up-regulation of spinal muscarinic receptors and increased antinociceptive effect of intrathecal muscarine in diabetic rats. J Pharmacol Exp Ther 307: 676-681.

17. Yang J, Pan Y, Zhao Y, Lu G, Lu L, et al. (2012) Acetylcholine participates in pain modulation by influencing endogenous opiate peptides in rat spinal cord. World J Neurosci 2: 15-22.

18. Neugebauer NM, Einstein EB, Lopez MB, McClure-Begley TD, Mineur YS, et al. (2013) Morphine dependence and withdrawal induced changes in cholinergic signaling. Pharmacol Biochem Behav 109: 77-83.

19. Menegatti R, Silva GM, Zapata-Sudo G, Raimundo JM, Sudo RT, et al. (2006) Design, synthesis, and pharmacological evaluation of new neuroactive pyrazolo[3,4-b]pyrrolo[3,4-d]pyridine derivatives with in vivo hypnotic and analgesic profile. Bioorg Med Chem 14: 632-640.

20. Mendes TC, Antunes F, Trachez MM, Nascimento NM Jr, Fraga CA, et al. (2013) Antihyperalgesic effects of a novel muscarinic agonist (LASSBio-873) in spinal nerve ligation in rats. Clin Exp Pharmacol Physiol 40: 404-411.

21. Mendes TCF, Raimundo JM, Nascimento-Junior NM, Fraga CAM, Barreiro EJ, et al. (2009) Sedation and antinociception induced by a new pyrazolo[3,4-b] pyrrolo[3,4-d] pyridine derivative (LASSBio-873) is modulated by activation of muscarinic receptors. Pharmacol Biochem Behav 94: 70-74.

22. Cai YQ, Chen SR, Han HD, Sood AK, Lopez-Berestein G, et al. (2009) Role of M2, M3, and M4 muscarinic receptor subtypes in the spinal cholinergic control of nociception revealed using siRNA in rats. J Neurochem 111: 1000-1010.

23. Landis SC, Amara SG, Asadullah K, Austin CP, Blumenstein R, et al. (2012) A call for transparent reporting to optimize the predictive value of preclinical research. Nature 490: 187-191.

24. Decosterd I, Woolf CJ (2000) Spared nerve injury: an animal model of persistent peripheral neuropathic pain. Pain 87: 149-158.

25. Hargreaves K, Dubner R, Brown F, Flores C, Joris J (1988) A new and sensitive method for measuring thermal nociception in cutaneous hyperalgesia. Pain 32: 77-88.

26. Vivancos GG, Verri WA Jr, Cunha TM, Schivo IR, Parada CA, et al. (2004) An electronic pressure-meter nociception paw test for rats. Braz J Med Biol Res 37: 391-399.

27. Pettersen VL, Zapata-Sudo G, Raimundo JM, Trachez MM, Sudo RT (2009) The synergistic interaction between morphine and maprotiline after intrathecal injection in rats. Anesth Analg 109: 1312-1317.

28. Haga K, Kruse AC, Asada H, Yurugi-Kobayashi T, Shiroishi M, et al. (2012) Structure of the human M2 muscarinic acetylcholine receptor bound to an antagonist. Nature 482: 547-551.

29. Iwai S, Kiguchi N, Kobayashi Y, Fukazawa Y, Saika F, et al. (2012) Inhibition of morphine tolerance is mediated by painful stimuli via central mechanisms. Drug Discov Ther 6: 31-37.

30. Ozdemir E, Bagcivan I, Gursoy S (2012) Modulation of morphine analgesia and tolerance in rats by NMDA receptor antagonists. Neurophysiology 44: 123-130.

31. Horvath RJ, Romero-Sandoval EA, De Leo JA (2010) Inhibition of microglial P2X4 receptors attenuates morphine tolerance, Iba, GFAP and $\mu$ opioid receptor protein expression while enhancing perivascular microglial ED2. Pain 150: 401-413.

32. Mendes TCF (2010) Desenvolvimento de novas substâncias neuroativas derivadas do zolpidem para o tratamento da dor neuropática. Thesis presented to the Post-Graduation Program in Pharmacology and Medicinal Chemistry, Federal University of Rio de Janeiro.

33. Jun IG, Kim SH, Yoon YI, Park JY (2013) Intrathecal lamotrigine attenuates antinociceptive morphine tolerance and suppresses spinal glial cell activation in morphine-tolerant rats. J Korean Med Sci 28: 300-307.

34. Chavooshi B, Saberi M, Pournaghash Tehrani S, Bakhtiarian A, Ahmadiani A, et al. (2009) Vigabatrin attenuates the development and 
Citation: Monteiro CES, Nascimento-Júnior NM, Trachez MM, Tesch R, Mendes TCF, et al. (2015) Prevention and Reversal of MorphineInduced Tolerance by Novel Muscarinic Receptor Agonist in Rats with Neuropathic Pain. J Neurol Neurophysiol 6: 282. doi: $10.4172 / 2155-9562.1000282$

Page 7 of 7

expression of tolerance to morphine-induced antinociception in mice. Pharmacol Biochem Behav 93: 155-159.

35. Lin JA, Lee MS, Wu CT, Yeh CC, Lin SL, et al. (2005) Attenuation of morphine tolerance by intrathecal gabapentin is associated with suppression of morphine-evoked excitatory amino acid release in the rat spinal cord. Brain Res 1054: 167-173.

36. Tai YH, Wang YH, Wang JJ, Tao PL, Tung CS, et al. (2006) Amitriptyline suppresses neuroinflammation and up-regulates glutamate transporters in morphine-tolerant rats. Pain 124: 77-86.

37. Zhang HM, Chen SR, Pan HL (2007) Regulation of glutamate release from primary afferents and interneurons in the spinal cord by muscarinic receptor subtypes. J Neurophysiol 97: 102-109.

38. Yoon MH, Choi JI, Jeong SW (2003) Antinociception of intrathecal cholinesterase inhibitors and cholinergic receptors in rats. Acta Anaesthesiol Scand 47: 1079-1084.
39. Prado WA, Dias TB (2009) Postoperative analgesia induced by intrathecal neostigmine or bethanechol in rats. Clin Exp Pharmacol Physiol 36: 648-654.

40. Cheng LZ, Han L, Fan J, Huang LT, Peng LC, et al. (2011) Enhanced inhibitory synaptic transmission in the spinal dorsal horn mediates antinociceptive effects of TC-2559. Mol Pain 7: 56.

41. Honda K, Ando S, Koga K, Takano Y (2004) The spinal muscarinic receptor subtypes contribute to the morphine-induced antinociceptive effects in thermal stimulation in mice. Neurosci Lett 371: 235-238.

42. Gregory KJ, Hall NE, Tobin AB, Sexton PM, Christopoulos A (2010) Identification of orthosteric and allosteric site mutations in M2 muscarinic acetylcholine receptors that contribute to ligand-selective signaling bias. J Biol Chem 285: 7459-7474. 